\title{
USING RECENT ADVANCES IN 2D SEISMIC TECHNOLOGY AND SURFACE GEOCHEMISTRY TO ECONOMICALLY \\ REDEVELOP A SHALLOW SHELF CARBONATE RESERVOIR: VERNON FIELD, ISABELLA COUNTY, MI.
}

TYPE OF REPORT: QUARTERLY

REPORTING PERIOD START DATE: OCTOBER 1, 2003

REPORTING PERIOD END DATE: DECEMBER 31, 2003

PRINCIPAL AUTHORS:

JAMES R. WOOD, MICHIGAN TECHNOLOGICAL UNIVERSITY, HOUGHTON, MI A. WYLIE, MICHIGAN TECHNOLOGICAL UNIVERSITY, HOUGHTON, MI W. QUINLAN, JORDAN EXPLORATION COMPANY LLC, TRAVERSE CITY, MI.

DATE REPORT WAS ISSUED: JANUARY, 2004

DOE AWARD NUMBER: DE-FC26-00BC15122

NAME AND ADDRESS OF SUBMITTING ORGANIZATION:

MICHIGAN TECHNOLOGICAL UNIVERSITY 1400 TOWNSEND DRIVE HOUGHTON, MI. 49931 


\section{DISCLAIMER}

This report was prepared as an account of work sponsored by an agency of the United States Government. Neither the United States Government nor any agency thereof, nor any of their employees, makes any warranty, express or implied, or assumes any legal liability or responsibility for the accuracy, completeness, or usefulness of any information, apparatus, product or process disclosed, or represents that its use would not infringe on any privately owned rights. Reference herein to any specific commercial product, process, or service by trade name, trademark, manufacturer, or otherwise, does not necessarily constitute or imply its endorsement, recommendation or favoring by the United States Government nor any agency thereof. The views and opinions of authors expressed herein do not necessarily state or reflect those of the United States Government. 


\begin{abstract}
The principal objective of this demonstration project is to test surface geochemical techniques for detecting trace amounts of light hydrocarbons in pore gases as a means of reducing risk in hydrocarbon exploration and production. During this reporting period, a new field demonstration, Springdale Prospect in Manistee County, Michigan was begun to assess the validity and usefulness of the microbial surface geochemical technique. The surface geochemistry data showed a fair-to-good microbial anomaly that may indicate the presence of a fault or stratigraphic facies change across the drilling path.

The main news this reporting period is the confirmed discovery of producing hydrocarbons at the State Springdale \& O'Driscoll \#16-16 demonstration well in Manistee County. This well was spudded in late November, tested and put on production in December 2003. To date it is flowing nearly 100 barrels of liquid hydrocarbons per day, which is a good well in Michigan. Reserves have not been established yet.

The surface geochemistry sampling at the Springdale demonstration site will be repeated this spring after the well has been on production for several months to see if the anomaly pattern changes. We expect that the anomaly will diminish as the original positive (apical) anomaly is replaced by a negative (edge) anomaly, probably due to the pressure draw-down in the reservoir. This is the behavior that we observed at the Bear lake demonstration well reported last quarter.
\end{abstract}




\section{TABLE OF CONTENTS}

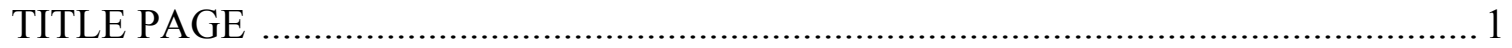

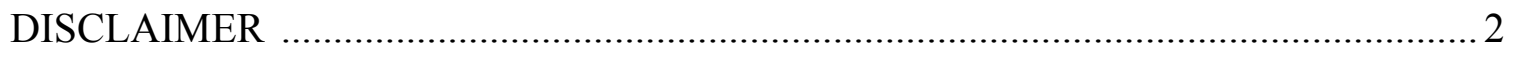

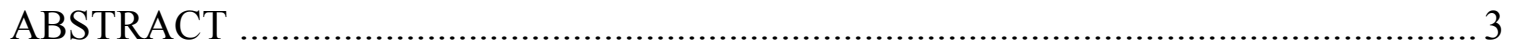

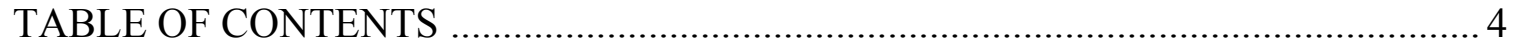

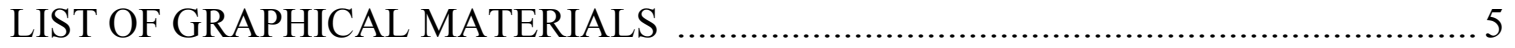

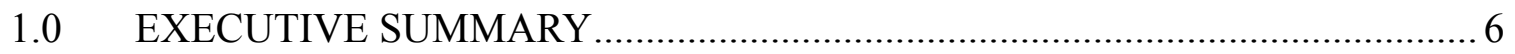

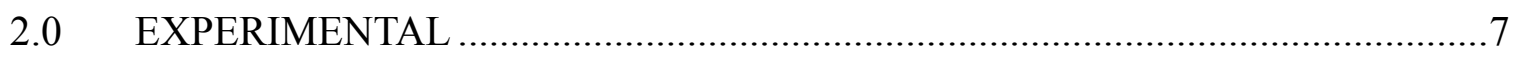

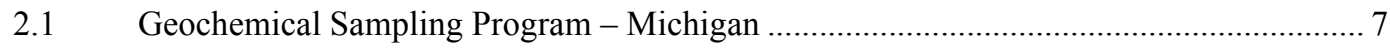

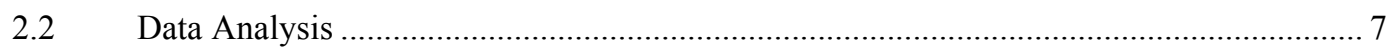

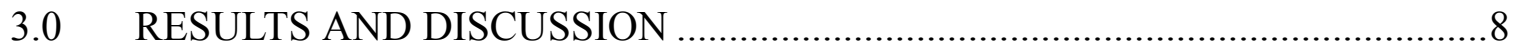

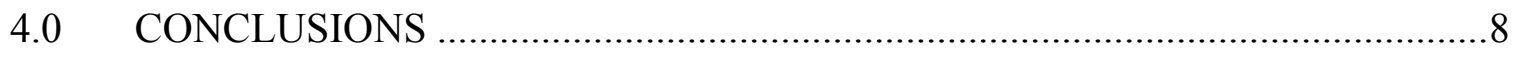

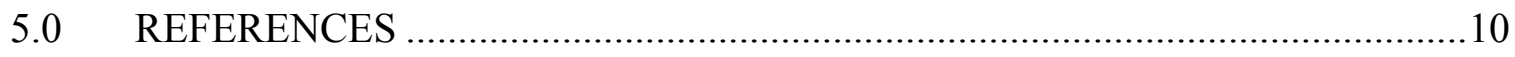

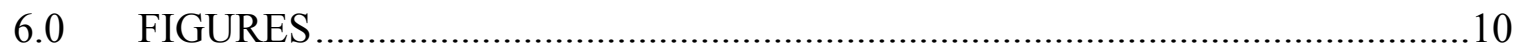




\section{LIST OF GRAPHICAL MATERIALS}

Figure 1. Index map showing locations of all geochemical sampling in Michigan.

Figure 2. State Springdale \& O'Driscoll 16-16 HD1 daily production data from 11/8/2003 through $1 / 11 / 2004$.

Figure 3. Generalized Stratigraphic Column for the Michigan Basin.

Figure 4. Microbial contour map of the Springdale Prospect in Manistee County, Michigan. Red well path is St. Springdale \& O'Driscoll 16-16 HD1. Large red circle is bottom hole location (bhl) with permit number, 55782. Red contours indicate high microbial anomalies and blue contours indicate low anomalies. 


\subsection{EXECUTIVE SUMMARY}

\section{New Findings}

The project has located hydrocarbons at the Springdale demonstration site (Figure 1) and has begun production from the State Springdale-O'Driscoll \#16-16 at 100 barrels of oil per day and 100 mcf of gas per day, on average (Figure 2). Production is from the Brown Niagaran (Figure 3) interval, from 5124 to 5798 feet, measured depth. This well was located on a mild geochemical anomaly (Figure 4) and a second follow-up well is planned in the southwest quarter of section 16 early in 2004.

\section{Lessons Learned}

Again the basic lesson is that geochemical surveys should precede drilling in Michigan prospects. The Springdale success was preceded by a geochemical survey that did not condemn the prospect. However, it appears that geochemical surveys over developed fields have to be interpreted with caution due to the disturbances caused by production (e.g. pressure drawdown) which seem to produce negative or apical anomalies in the vicinity of the well bore extending out at least $1 / 2$ mile. Perseverance and patience are also virtues in this type of exploration, as well as adopting a consistent set of sample procedures.

\section{Should Something Else Have Been Done?}

We should have stipulated that all project demonstrations had to have surface geochemistry surveys included in the prospectus, that is, as part of the package used to sell the prospect to investors. This would both educate the gas and oil community as to the value of geochemistry as well as insure that we are notified sufficiently in advance of the drilling to make better sampling plans and have an opportunity to conduct a "fill-in" geochemical survey if the original survey shows gaps and/or holes.

\section{Goals and Results}

One main goal of this project was to locate and produce hydrocarbons using surface geochemistry as a screening tool. The Springdale project has come close to fulfilling those objectives with demonstrated liquid hydrocarbons in place and approximately 45 days of production at about 100 barrels/day. We intend to pursue the Springdale demonstration with additional wells and surveys to test areas in the near vicinity.

\section{Applications}

As mentioned before, the results of the Bear Lake, Vernon, Bagley, and North Dakota geochemical surveys, and now the Springdale survey, can be applied to other carbonate reservoirs worldwide. In particular, the application of appropriate surface geochemistry surveys seems warranted based on the work done here, as well as the advice to record the surveys at the same grid density as complimentary seismic data. We think that further analysis of the Springdale geochemical 
results combined with a thorough geological and engineering investigation can shed light on how to go after these types of plays.

\section{Did Data Support Project or Not?}

In regard to the Springdale project, the geochemical survey did not condemn it, but neither did it produce the kind of high anomalies that we have seen elsewhere (North Dakota, for example).

\section{Future Work}

More geochemical work will be done in conjunction with further field demonstrations as part of this project in Michigan and North Dakota. New demonstration wells are planned for Michigan to test the Silurian or Devonian reef plays. Preliminary results using both the charcoal adsorption and the microbial techniques show good anomaly patterns for the Silurian Niagaran reefs. Activated carbon sampling will be further evaluated in one or more demonstration areas.

\subsection{EXPERIMENTAL}

\subsection{Geochemical Sampling Program - Michigan}

The geochemical program will be focused now on Springdale, probably through the spring and summer of 2004. A wider area will be surveyed and new sampling techniques will be tested.

In the July-September, 2003 reporting period, as well as this period (October-December, 2003), the geochemical sampling program was extended with surveys conducted over three field sites in Michigan: Bear Lake, Springdale and Charlton 6 (Figure 1). Two types of samples were collected: soil samples for microbial analysis by Geo-Microbial Technologies (GMT) and activated charcoal samples for analysis at MTU. The soil samples were collected at depths of nominally 8 inches as per GMT protocols. The charcoal samples were buried 36 inches deep in glass vials with fine mesh screens over the tops and left in the ground 2-3 weeks. The samples were analyzed by gas chromatography.

\subsection{Data Analysis}

We have been analyzing duplicate samples from the surface geochemistry surveys at MTU using gas chromatography and comparing the result with the commercial microbial results. Full details of this comparative approach will be presented when sufficient data has been collected. 


\subsection{RESULTS AND DISCUSSION}

Analysis of the geology of the Springdale prospect will continue in the aftermath of the successful well there. The focus will be on the critical steps involved in discovering this play and the role of surface geochemistry. We hope to produce a detailed geological model for this field and integrate the geochemical data into it. Analysis of the project surface geochemical data has now shown some significant results. The major findings are that the large-scale survey at Vernon Field, conducted early on in this project, appears now to be best interpreted as a halo anomaly over a depleted field (Figure 3, Technical Quarterly Report \#15122R17, July-September 2003). And the surveys over the pinnacle reefs show that these structures appear to be well suited for geochemical imaging (Figures 4, 5, and 6, Technical Quarterly Report \#15122R17, July-September 2003). We obtained good positive apical anomalies over several structures in the reef trend that were confirmed by drilling. We also obtained our best results in the form of very good apical anomalies over the Williston Basin test site (Technical Quarterly Report \#15122R16, March-June 2003).

\subsection{CONCLUSIONS}

The positive results from the Springdale well show that live hydrocarbons can still be recovered in the Michigan Basin by small companies. We now need to establish the reserves and see if there are any further plays in the area. This work will likely stretch out over at least two years, but it is likely that much can be accomplished this summer, year 4 of this project. Thus, we should have a good case history to write up for the final report. In addition, the Springdale play will be presented at various meetings and symposia, including PTTC workshops in the coming years. The main questions now are: 1. the size of the reserves, 2. the presence of additional fields nearby, and 3. details of the geology, including the type of trap and how to locate them.

The geochemical sampling program has been the main activity over this reporting period and has produced some positive results, particularly over the Springdale demonstration site. It appears to show an abrupt transition from high to low values directly across the path of the proposed well. It would appear that additional sampling on a tighter grid would be useful here but we should reconcile the present data with the drilling results first.

The additional microbial sampling over the Bear Lake prospect has considerably widened the coverage there. It appears that the discovery well is now producing a negative (halo) anomaly due to the pressure draw-down and this is reflected in the microbial data. However several relative highs were picked up in the new survey that bear further investigation, preferably by $2 \mathrm{D}$ seismic lines to see if there is any structure associated with them.

In general, the geochemical program is proving a valuable addition to the demonstration program in this project. We have mapped both positive and negative anomalies over the demonstration sites and have been able to correlate these observations with production. In general the negative anomalies correlate with produced fields or with reefs that are currently pumping. Positive anomalies occur over prospects that have not been drilled and where at least shows of hydrocarbons were encountered in the subsequent tests. The extensive geochemical sampling over Vernon Field is now seen in retrospect to have defined a large negative anomaly associated with the entire field, 
indicating that it was a poor candidate for further development, a result confirmed by the drilling of the Smock 13-23-HD1 test well.

We have also developed a sampling and analysis protocol for surface geochemistry based on retrieval of activated carbon and analysis by gas chromatography. This technique is still being developed, but side-by-side comparisons with the microbial data can be used to compare the efficiency and accuracy (consistency) of the technique. If the activated carbon technique proves accurate, it has the advantage of being lower cost and more adaptable to routine application by small operators. We will emphasize this aspect of the project in our future reports. 


\subsection{REFERENCES}

\subsection{FIGURES}




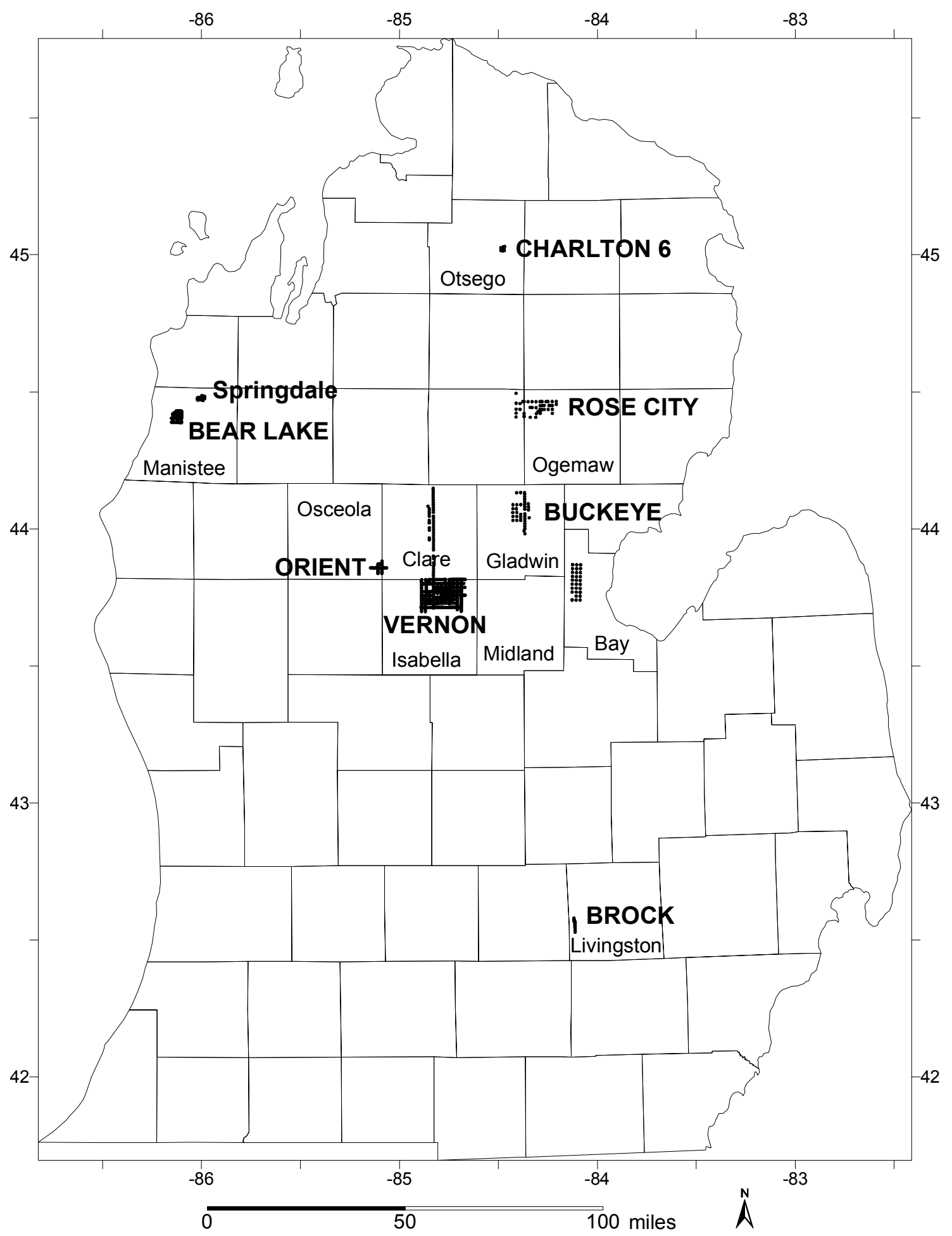

Figure 1. Index map showing locations of all geochemical sampling in Michigan. 


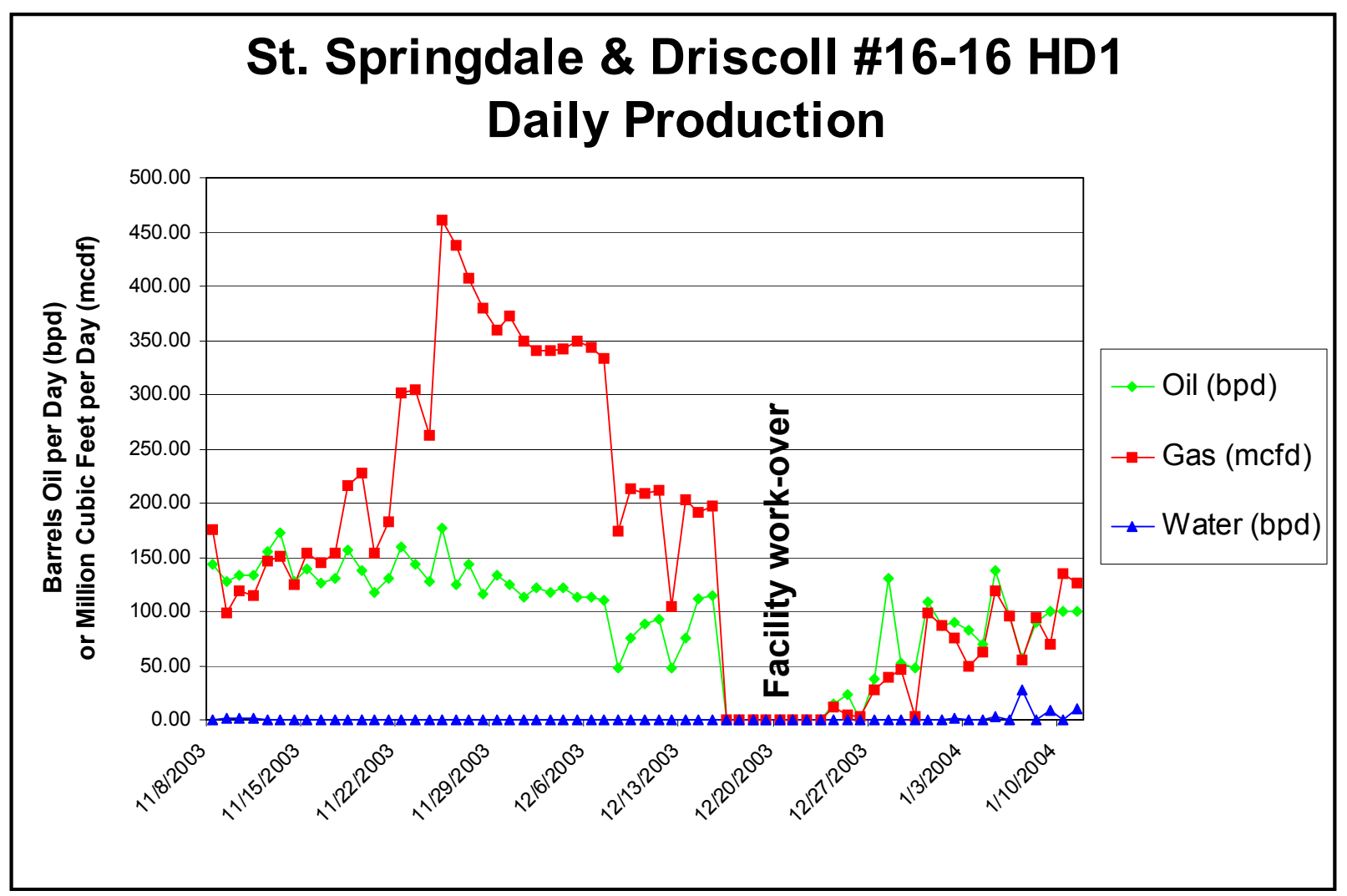

Figure 2. State Springdale \& O'Driscoll 16-16 HD1 daily production data from 11/8/2003 through 1/11/2004. 


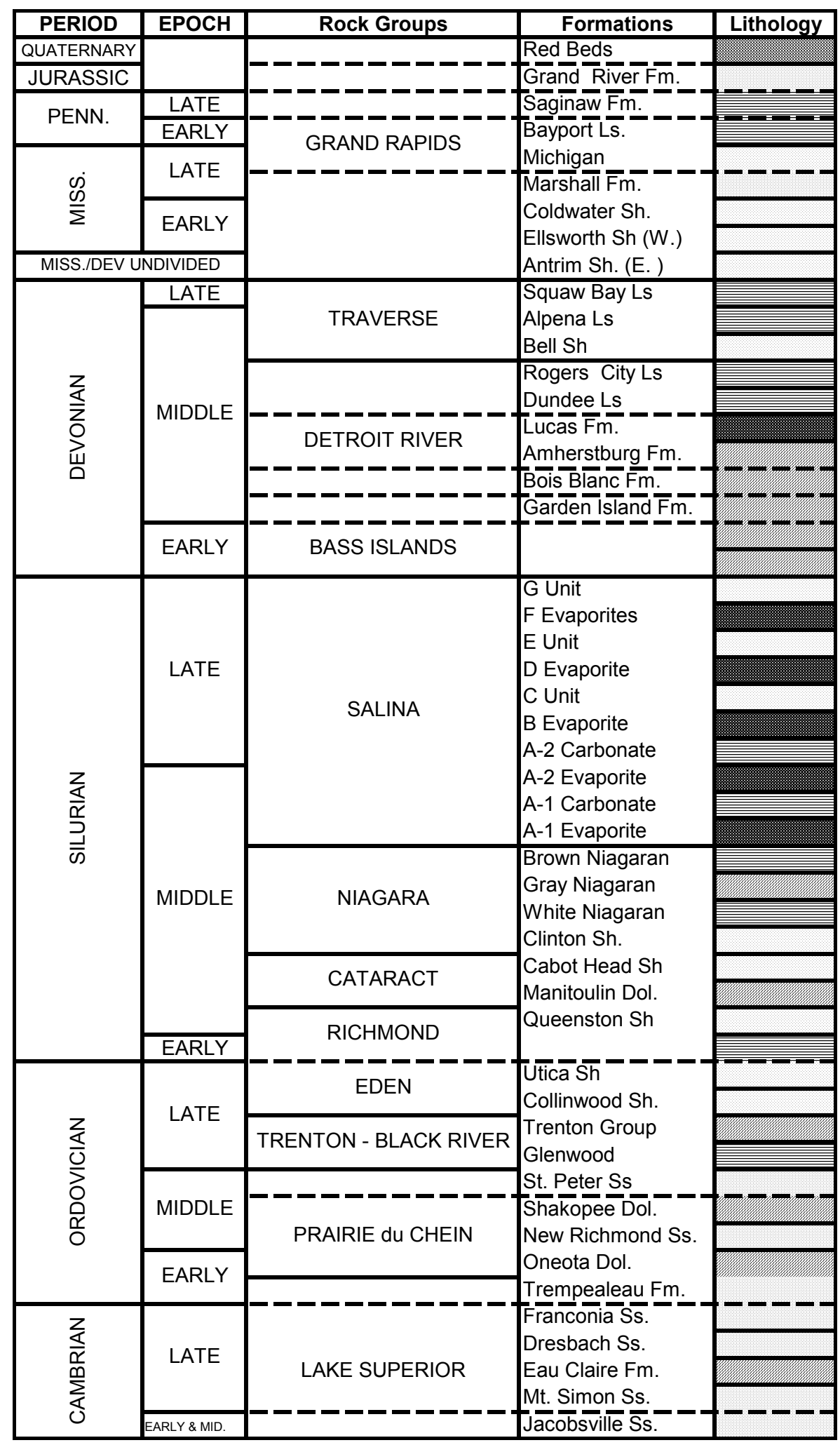

Figure 3. Generalized Stratigraphic Column for the Michigan Basin. 


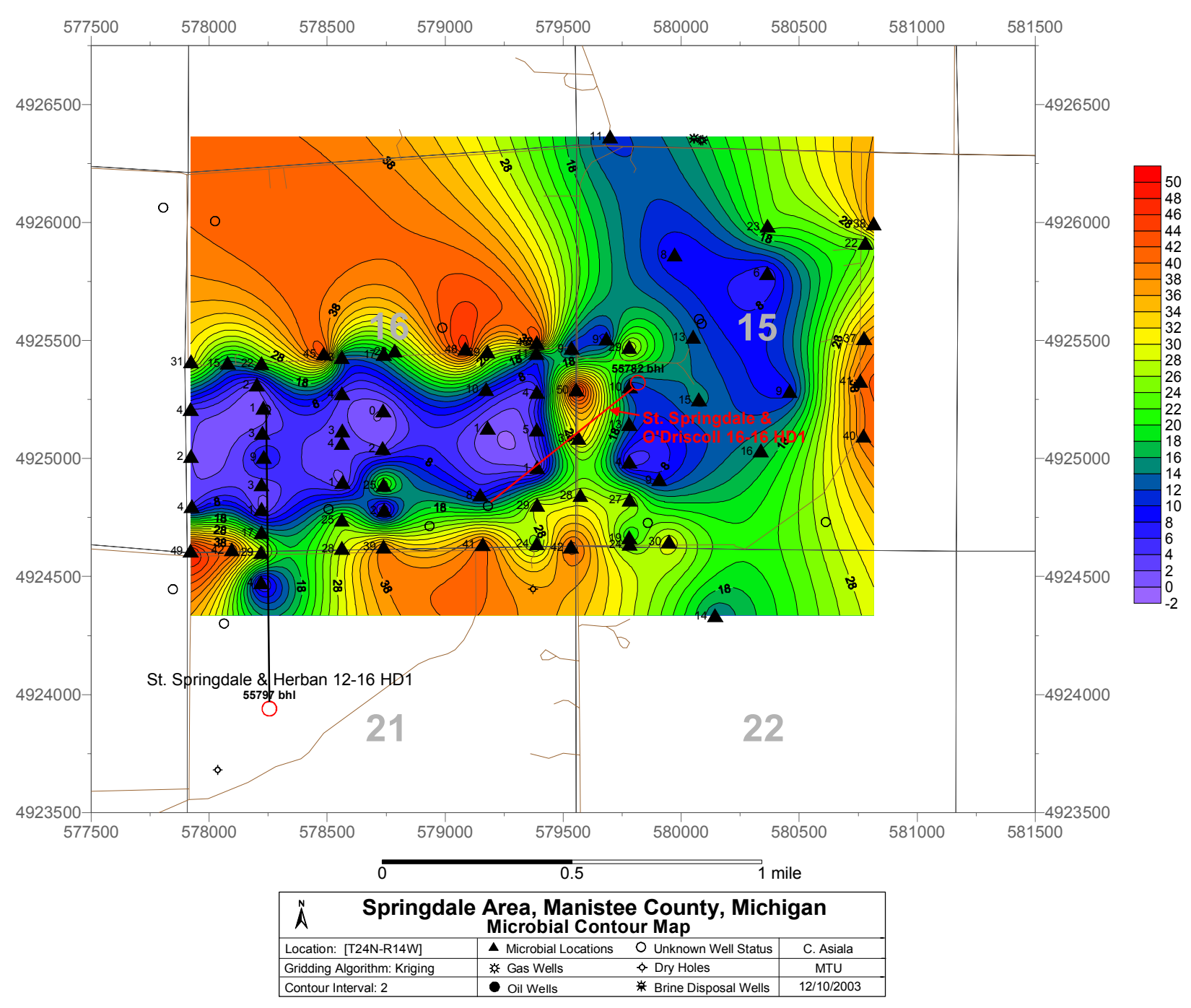

Figure 4. Microbial contour map of the Springdale Prospect in Manistee County, Michigan. Red well path is St. Springdale \& O'Driscoll 16-16 HD1. Large red circle is bottom hole location (bhl) with permit number, 55782. Red contours indicate high microbial anomalies and blue contours indicate low anomalies. 